\title{
PENENTUAN CADANGAN PREMI ASURANSI DWIGUNA MENGGUNAKAN METODE ILLINOIS BERDASARKAN HUKUM MORTALITAS WEIBULL
}

\author{
Ayu Eka Fanny Devi ${ }^{1 \S}$, I Nyoman Widana ${ }^{2}$, Ketut Jayanegara ${ }^{3}$ \\ ${ }^{1}$ Program Studi Matematika, Fakultas MIPA - Universitas Udayana [Email: ayuufanny14@gmail.com] \\ ${ }^{2}$ Program Studi Matematika, Fakultas MIPA - Universitas Udayana [Email: nwidana@yahoo.com] \\ ${ }^{3}$ Program Studi Matematika, Fakultas MIPA - Universitas Udayana [Email: ktjayanegara@unud.ac.id] \\ ${ }^{\S}$ Corresponding Author
}

\begin{abstract}
Endowment insurance provides protection benefit and saving benefits. In the endowment insurancethe insured party (insurance participant) must be paid the premiums. In addition to premiums, there is also policy value, which is sum of money that must be collected by the company in preparation for claim payment. The purpose of this study was to determine calculation of policy value in endowment insurance using Illinois method based on Weibull Mortality Law. In this study used secondary data from United States Life Table in the form of mortality probability data. Calculation value using Weibull mortality law, then the policy value calculated by Illinois method. The result of this study is policy value using Illinois Method based on Weibull Mortality Law is bigger than policy value using Illinois method without Weibull mortality law in the first year until year 20th. After year 20th, the policy value using Illinois method based on Weibull mortality law is smaller than policy value using Illinois method without Weibull mortality law, while at the end of the insurance year which is year 30th, the policy value with or without Weibull mortality law generates the same value.
\end{abstract}

Keywords: Endowment Insurance, Weibull Mortality Law, Policy Value, Illinois Method

\section{PENDAHULUAN}

Terdapat banyak risiko yang mungkin terjadi secara tidak terduga dimasa depan. Misalnya seperti kematian, kehilangan tempat tinggal, kecelakaan, sakit, dan kehilangan pekerjaan. Oleh karena itu perlu adanya perusahaan yang ditujukan untuk menghambat risiko-risiko sehingga tidak menimbulkan kerugian. Perusahaan asuransi merupakan lembaga yang dapat melindungi seseorang dari risiko dengan sejumlah polis asuransi. Pada artikel ini akan difokuskan pada asuransi jiwa dwiguna karena asuransi tersebut memberikan dua manfaat yaitu manfaat saat pemegang polis meninggal dalam periode tertentu dan manfaat jika pemegang polis masih hidup sampai masa akhir pertanggungan (Futami, 1993). Dalam asuransi dwiguna pemegang polis wajib untuk membayar premi sesuai kesepakatan antara pemegang polis dan perusahaan asuransi.

Pada artikel ini perhitungan premi dilakukan dengan menggunakan hukum mortalitas Weibull. Menurut Sembiring (1986) pendekatan dengan hukum mortalitas bertujuan agar hasil dari pendekatan akan berbentuk kontinu sehingga lebih praktis. Perusahaan asuransi tidak hanya perlu menentukan besar premi tetapi juga besar cadangan premi. Pada awal tahun nilai pengeluaran perusahaan asuransi sering kali lebih besar dibandingkan tahun-tahun berikutnya. Oleh karena itu, perlu adanya penyesuaian dalam perhitungan cadangan premi. Salah satu metode yang dapat digunakan dalam perhitungan cadangan premi disesuaikan adalah metode Illinois (Sembiring, 1986). Metode Illinois adalah metode perhitungan cadangan dengan menggunakan premi bersih lanjutan yang disesuaikan. Hal tersebut bermakna bahw a premi bersih asuransi dwiguna digantikan oleh premi yang perhitungannya menyesuaikan tahun pembayarannya.

Perhitungan cadangan premi berdasarkan hukum mortalitas Weibull sebelumnya telah dilakukan oleh Widia \& Subhan (2019) dengan menggunakan metode New Jersey. Hasil dari 
penelitian tersebut adalah nilai cadangan pada tahun pertama adalah nol dan tahun berikutnya mengalami peningkatan setiap tahunnya.

Terkait menentukan nilai cadangan premi menggunakan metode Illinois pernah dilakukan oleh Lestari et al. (2019). Penelitian tersebut memeroleh hasil bahwa metode Illinois menghasilkan nilai cadangan yang lebih kecil dibandingkan dengan metode prospektif tanpa metode Illinois.

Berdasarkan penelitian terdahulu dan melihat keunggulan dari hukum mortalitas Weibull dalam menentukan nilai premi serta metode Illinois dalam menentukan nilai cadangan premi. Peneliti tertarik untuk membahas mengenail Penentuan Cadangan Premi Asuransi Dwiguna Menggunakan Metode Illinois Berdasarkan Hukum Mortalitas Weibull.

Pada distribusi Weibull, fungsi laju angka kematian dinotasikan dengan

$$
\mu(x)=\left(\frac{\alpha}{\beta}\right)\left(\frac{x}{\beta}\right)^{\alpha-1}
$$

(Bowers et al., 1997)

Fungsi laju angka kematian berpengaruh pada penentuan peluang hidup tertanggung dalam perhitungan premi. Premi tahunan bersih asuransi jiw a dwiguna dinotasikan dengan:

$$
P_{x: \bar{n} \mid}=\frac{A_{x: \overline{n \mid}}}{\ddot{a}_{x: \bar{n} \mid}}
$$

Setelah penentuan premi, maka dapat ditentukan besar cadangan premi. Menurut Sembiring (1986) cadangan premi dengan menggunakan metode Illinois yaitu:

$$
\begin{aligned}
{ }_{t} V= & A_{x+t: \overline{n-t \mid}}-\beta^{I} \ddot{a}_{x+t: \overline{20-t \mid}} \\
& -{ }_{m} P_{x: \bar{n} \mid}\left(20-t \mid m-20 \ddot{a}_{x+t}\right) \\
{ }_{t} V= & A_{x+t: \overline{n-t \mid}} \\
& -{ }_{m} P_{x: \bar{n}} \ddot{a}_{x+t: \overline{m-t \mid}} \\
{ }_{t} V= & A_{x+t: \overline{n-t \mid}}
\end{aligned}
$$

Persamaan (3) digunakan dalam menentukan cadangan premi untuk $t \leq 20$, persamaan (4) digunakan dalam menentukan cadangan premi untuk $20<t \leq m$, dan persamaan (5) digunakan dalam menentukan cadangan premi untuk $m<t \leq n$.

\section{METODE PENELITIAN}

Dalam penelitian ini digunakan data sekunder yaitu data life tabel Amerika Serikat tahun 2017 yang berisikan data peluang kamatian. Adapun langkah-langkah dalam penelitian ini adalah sebagai berikut

1. Menggunakan polis asuransi

2. Melakukan estimasi parameter distribusi Weibull terhadap data life table Amerika Serikat tahun 2017 dengan bantuan software $\mathrm{R}$.

3. Menggunakan data life table Amerika Serikat untuk memperoleh tabel komutasi.

4. Menghitung cadangan premi asuransi dwiguna menggunakan metode Illinois berdasarkan persamaan (3) dan (4).

5. Menentukan formula premi asuransi jiwa dwiguna berdasarkan hukum mortalitas Weibull.

6. Mengitung nilai premi asuransi dwiguna berdasarkan hukum mortalitas Weibull.

7. Menentukan formula cadangan premi dengan menggunakan metode Illinois berdasarkan hukum mortalitas Weibull.

8. Menghitung cadangan premi dengan metode Illinois menggunakan hukum mortalitas Weibull.

9. Interpretasi hasil.

\section{HASIL DAN PEMBAHASAN}

\subsection{Pendugaan Parameter Distribusi Weibull terhadap Life Table Amerika Serikat 2017}

Penentuan parameter distribusi Weibull terhadap data peluang kematian pada life table Amerika Serikat tahun 2017 menggunakan Maximum Likelihood Estimation. Melalui bantuan software $\mathrm{R}$, diperoleh parameter distribusi Weibull yaitu $\alpha=0,4549$ dan $\beta=$ 16,6383 .

Setelah diperoleh hasil pendugaan parameter distribusi Weibull, selanjutnya dilakukan uji data peluang kematian pada life table Amerika Serikat 2017 berdistribusi Weibul. Uji kecocokan data distribusi Weibull dilakukan dengan menggunakan Uji Kolmogorov-Smirnov. Melalui bantuan software $\mathrm{R}$ diperoleh hasil $\mathrm{p}$-value $=0,3287 \geq$ $\alpha=0,05$ sehingga keputusan yang diambil adalah terima $H_{0}$ yaitu data peluang kematian pada life table Amerika Serikat berdistribusi Weibull.

\subsection{Tabel Komutasi untuk Asuransi Dwiguna}

Menurut Dickson et al (2009) tabel komutasi diperoleh dengan menghitung terlebih dahulu nilai-nilai fungsi komutasi. Penentuan nilai $d_{x}$ 
dilakukan sebelum menghitung nilai-nilai fungsi komutasi dengan menggunakan persamaan

$$
d_{x}=l_{x}-l_{x+1}
$$

Sehingga diperoleh nilai $d_{x}$ seperti berikut:

$d_{30}=l_{30}-l_{31}=132,23$

$d_{31}=l_{31}-l_{32}=137,03$

$\vdots$

$d_{60}=l_{60}-l_{61}=802,24$

Kemudian dengan menggunakan $i=5 \%$ maka diperoleh:

a. Nilai $v$ dapat ditentukan berdasarkan persamaan:

$$
v=\frac{1}{1+i}=0,9524
$$

b. Nilai $D_{x}$ dapat ditentukan berdasarkan persamaan:

Diperoleh:

$$
D_{x}=v^{x} l_{x}
$$

$D_{30}=22.645,3969$

$D_{31}=21.537,9076$

:

$D_{100}=14,4008$

c. Nilai $N_{x}$ dapat ditentukan berdasarkan persamaan:

$$
N_{x}=D_{x}+D_{x+1}+D_{x+2}+\cdots
$$

Sehingga diperoleh:

$N_{30}=421.434,8314$

$N_{31}=398.789,4346$

!

$N_{100}=14,4008$

d. Nilai $C_{x}$ dapat ditentukan berdasarkan persamaan:

Diperoleh:

$$
C_{x}=v^{x+1} d_{x}
$$

$C_{30}=29,1371$

$C_{31}=28,7582$

$\vdots$

$C_{100}=13,7151$

e. Nilai $M_{x}$ ditentukan berdasarkan persamaan:

$$
M_{x}=C_{x}+C_{x+1}+C_{x+2}+\cdots
$$

Sehingga diperoleh:

$M_{30}=2.577,0716$

$M_{31}=2.547,9345$

$\vdots$

$M_{100}=13,7151$

\subsection{Perhitungan Cadangan Premi Asuransi Dwiguna Menggunak an Metode Illinois tanpa Berdasarkan Hukum Mortalitas Weibull}

Polis asuransi yang digunakan adalah sebagai berikut: peserta asuransi berusia 30 tahun mengikuti asuransi jiw a dwiguna dalam jangka waktu 30 tahun. Apabila peserta asuransi meninggal atau tetap hidup dalam masa pertanggungan, maka peserta asuransi akan mendapatkan uang pertanggungan. Jumlah uang pertanggungan yang diberikan yaitu sebesar Rp 10.000.000,00.

Hal pertama yang harus dilakukan dalam menentukan cadangan premi adalah menghitung nilai premi tahunan pada asuransi dwiguna. Berdasarkan polis yang ditetapkan maka persamaan (2) dapat dimodifikasi menjadi:

$$
\begin{aligned}
& P_{30: \overline{30 \mid}}=\frac{A_{30: \overline{30 \mid}}}{\ddot{a}_{30: \overline{30 \mid}}}=10^{7} \frac{\frac{M_{30}-M_{60}+D_{60}}{D_{30}}}{\frac{N_{30}-N_{60}}{D_{30}}} \\
& =157.547,4728
\end{aligned}
$$

Selanjutnya ditentukan premi yang disesuaikan berdasarkan persamaan

$$
\beta^{I}=P_{x: \bar{n} \mid}+\frac{{ }_{19} P_{x+1}-\left(S\left(\frac{C_{x}}{D_{x}}\right)\right)}{\ddot{a}_{x: \bar{k} \mid}}
$$

Berdasarkan polis diperoleh

$$
\begin{aligned}
\beta^{I} & =P_{30: \overline{30 \mid}}+\frac{{ }_{19} P_{31}-\left(S\left(\frac{C_{30}}{D_{30}}\right)\right)}{\ddot{a}_{30: \overline{20}}} \\
& =163.866,5910
\end{aligned}
$$

Langkah berikutnya adalah menentukan nilai $\alpha^{I}$ menggunakan persamaan

$$
\alpha^{I}=\beta^{I}-\left({ }_{19} P_{x+1}-\left(\frac{C_{30}}{D_{30}}\right)\right)
$$

Berdasarkan polis yang telah ditetapkan berlaku:

$$
\begin{aligned}
\alpha^{I} & =\beta^{I}-\left({ }_{19} P_{31}-S\left(\frac{C_{30}}{D_{30}}\right)\right) \\
& =82.276,0911
\end{aligned}
$$

Berdasarkan persamaan (3) dan (4) maka nilai cadangan premi asuransi dwiguna menggunakan metode Illinois tanpa berdasarkan hukum mortalitas Weibull dapat dilihat pada Gambar 1. 


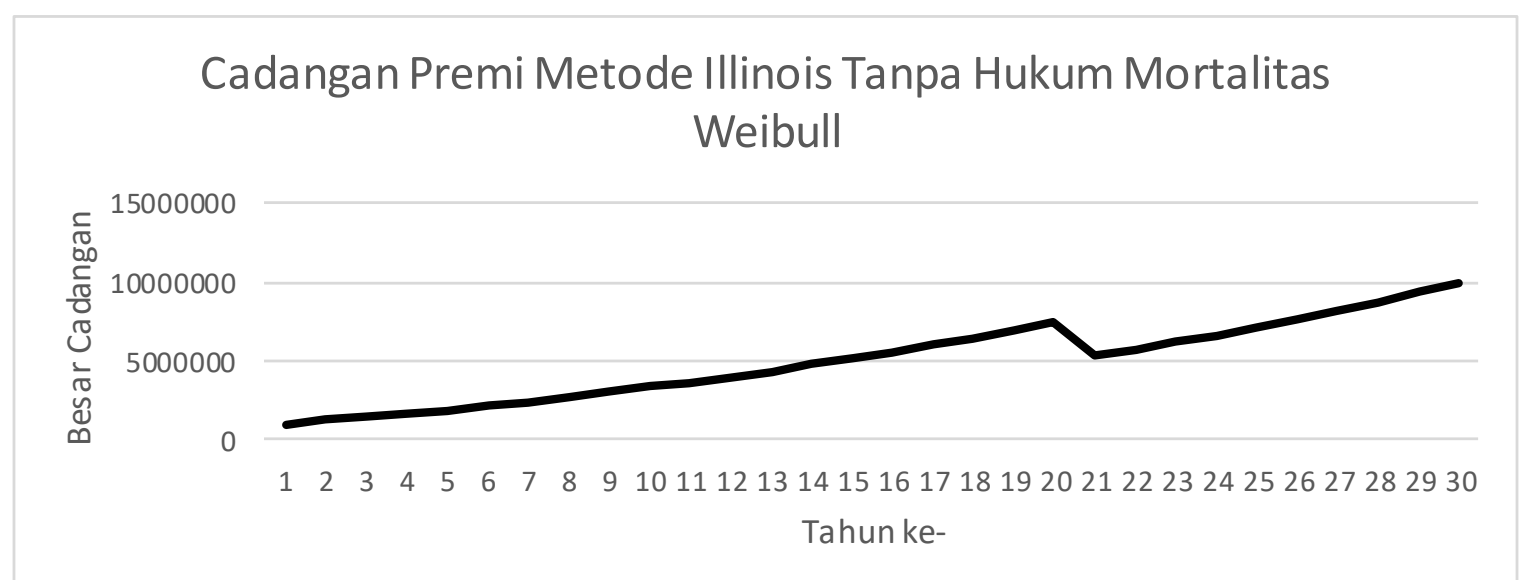

Gambar 1. Cadangan Premi Menggunakan Metode Illinois Tanpa Berdasarkan Hukum Mortalitas Weibull

\subsection{Penentuan Formula Premi Asuransi Dwiguna Berdasark an Hukum Mortalitas Weibull}

Langkah pertama dalam penentuan formula premi adalah menentukan formula peluang orang berusia $x$ tahun hidup sampai usia $x+t$ tahun $\left({ }_{t} p_{x}\right)$. Persamaan yang digunakan untuk menentukan formula ${ }_{t} p_{x}$ adalah sebagai berikut:

$$
{ }_{t} p_{x}=e^{-\int_{x}^{x+t} \mu(y) d y}
$$

Berdasarkan persamaan (1) diperoleh

$$
{ }_{t} p_{x}=\exp \left[-\left(\frac{(x+t)^{\alpha}-x^{\alpha}}{\beta^{\alpha}}\right)\right]
$$

Langkah selanjutnya adalah menentukan anuitas hidup berdasarkan persamaan

$$
\ddot{a}_{x: \bar{n} \mid}=\sum_{t=0}^{t-1} v^{t}{ }_{t} p_{x}
$$

Sehingga berdasarkan persamaan (6) diperoleh:

$$
\ddot{a}_{x: \bar{n} \mid}=\sum_{t=0}^{t-1} v^{t}\left(\exp \left[-\left(\frac{(x+t)^{\alpha}-x^{\alpha}}{\beta^{\alpha}}\right)\right]\right)
$$

Kemudian ditentukan formula premi tunggal asuransi dwiguna berdasarkan persamaan

$$
A_{x: \bar{n} \mid}=1-d\left(\ddot{a}_{x: \bar{n} \mid}\right)
$$

Sehingga sesuai dengan persamaan diperoleh:

$$
A_{x: \bar{n} \mid}=1-(1-v)(B)
$$

Dengan

$$
B=\sum_{t=0}^{t-1} v^{t}\left(\exp \left[-\left(\frac{(x+t)^{\alpha}-x^{\alpha}}{\beta^{\alpha}}\right)\right]\right)
$$

\subsection{Perhitungan Nilai Premi Asuransi Dwiguna Berdasarkan Huk um Mortalitas Weibull}

a. Nilai anuitas hidup asuransi dwiguna berdasarkan persamaan (7) diperoleh:

$$
\ddot{a}_{30: \overline{30 \mid}}=13,4442
$$

b. Nilai premi tunggal bersih asuransi dwiguna berdasarkan persamaan (8) diperoleh:

$$
A_{30: \overline{30 \mid}}=3.597 .984,9520
$$

Kemudian diperoleh nilai premi asuransi dwiguna berdasarkan hukum mortalitas Weibull sebagai berikut:

$$
P_{30: \overline{30 \mid}}=\frac{A_{30: \overline{30 \mid}}}{\ddot{a}_{30: 30 \mid}}=267.622,9522
$$

\subsection{Menentukan Formula Cadangan Premi \\ Menggunak an Metode Illinois \\ Berdasarkan Huk um Mortalitas Weibull}

Pada penentuan formula cadangan premi dengan metode Illinois berdasarkan hukum mortalitas Weibull, ditentukan terlebih dahulu premi yang disesuaikan berdasarkan persamaan

$$
\beta^{I}=P_{x: \bar{n} \mid}+\frac{{ }_{19} P_{x+1}-\left(S\left(\frac{C_{x}}{D_{x}}\right)\right)}{\ddot{a}_{x: \bar{k} \mid}}
$$

Sesuai dengan polis yang telah ditetapkan berlaku:

$$
\beta^{I}=P_{30: \overline{30 \mid}}+\frac{{ }_{19} P_{31}-\left(S\left(\frac{C_{30}}{D_{30}}\right)\right)}{\ddot{a}_{30: \overline{20} \mid}}
$$

Dengan menggunakan persamaan (7) dan (8) maka diperoleh:

$$
\beta^{I}=275.826,2952
$$

Selanjutnya ditentukan nilai $\alpha^{I}$ dengan 
mensubtitusi $\beta^{I}=275.826,2952$ diperoleh $\alpha^{I}=182.432,3478$.

Selanjutnya, menentukan nilai cadangan premi menggunakan metode Illinois.
Berdasarkan persamaan (3) dan (4) diperoleh

$$
\begin{aligned}
{ }_{1}^{30} V^{(I)}= & A_{31: \overline{29 \mid}}-\beta^{I} \ddot{a}_{31: \overline{19 \mid}} \\
& -{ }_{30} P_{30: \overline{30 \mid}}\left(\begin{array}{l}
19 \mid 10 \ddot{a}_{31}
\end{array}\right) \\
= & 1.170 .005,0680
\end{aligned}
$$

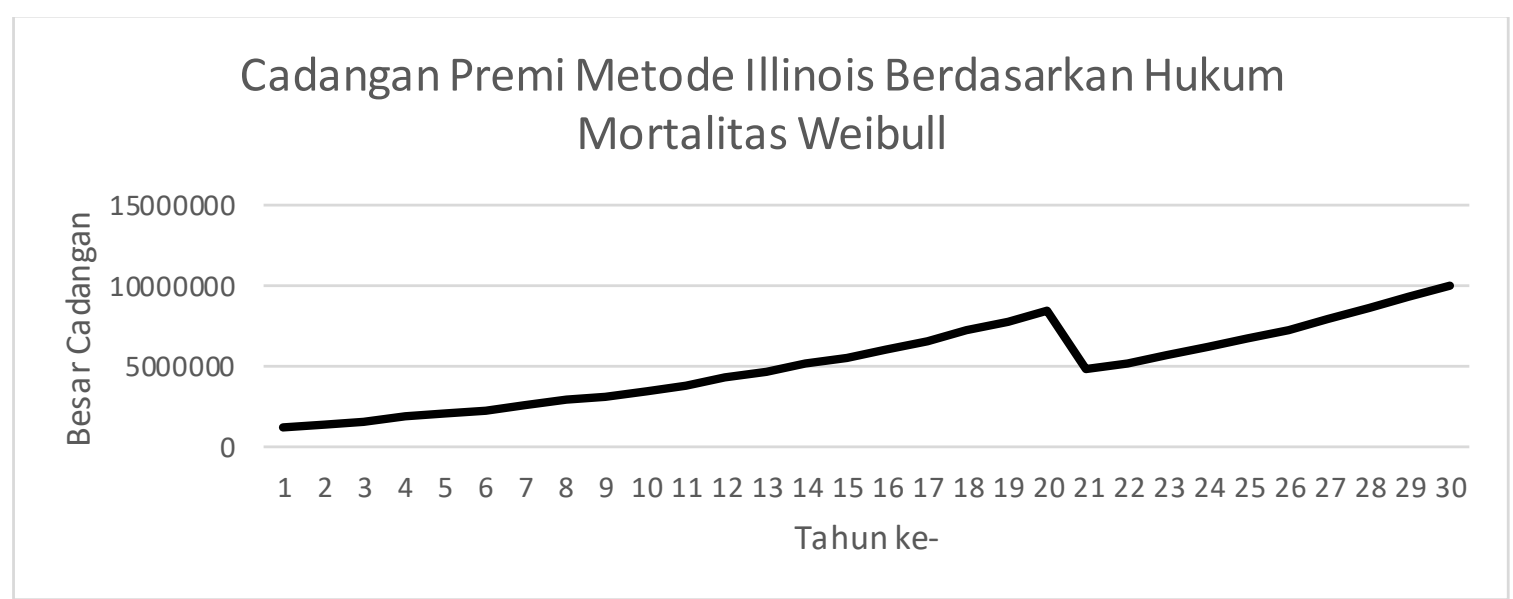

Gambar 2. Cadangan Premi Metode Illinois Berdasarkan Hukum Motralita Weibull

\section{KESIMPULAN DANSARAN}

Kesimpulan yang dapat diperoleh dari artikel ini adalah premi asuransi dwiguna dapat ditentukan dengan menggunakan hukum mortalitas Weibull yaitu melalui modifikasi formula peluang hidup tertanggung. Formula peluang hidup tertanggung berdasarkan hukum mortalitas Weibull adalah

$$
{ }_{t} p_{x}=\exp \left[-\left(\frac{(x+t)^{\alpha}-x^{\alpha}}{\beta^{\alpha}}\right)\right]
$$

Setelah premi diperoleh, cadangan premi ditentukan dengan menggunakan metode Illinois. Cadangan premi yang dihasilkan dengan menggunakan metode Illinois berdasarkan hukum mortalitas Weibull yaitu sebesar Rp 1.170.005,00 pada tahun pertama

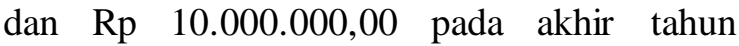
pertanggungan yaitu tahun ke-30. Cadangan premi pada tahun pertama sampai tahun ke-20 berdasarkan hukum mortalitas Weibull lebih besar dibandingkan cadangan premi tanpa menggunakan hukum mortalitas Weibull. Setelah tahun ke-20 cadangan premi berdasarkan hukum mortalitas Weibull lebih kecil dibandingkan dengan cadangan premi tanpa hukum mortalitas Weibull. Pada akhir tahun pertanggungan, cadangan premi yang dihasilkan baik dengan hukum mortalitas Weibull atau tanpa mortalitas Weibull sama besar.
Dalam artikel ini cadangan premi dengan menggunakan metode Illinois berdasarkan hukum mortalitas Weibull hanya dapat digunakan untuk polis yang menanggung satu peserta asuransi. Pada artikel selanjutnya disarankan penentuan cadangan premi asuransi dwiguna dengan menggunakan metode Illinois berdasarkan hukum mortalitas Weibull didesain untuk dua atau lebih tertanggung.

\section{DAFTAR PUSTAKA}

Bowers, N. L., Gerber, H. U., Hickman, J. C., Jones, D. A., \& Nesbitt, C. J. 1997. Actuarial Mathematics. Schaumburg: The Society Of Avtuaries.

Dickson, D. C. M., Hardy, M. R., \& Waters, H. R. 2009. Actuarial Mathematics For Life Contingent Risk. New York: Cambridge University Press.

Futami, T. 1993. Matematika Asuransi Jiwa, Bagian I (1st ed.). Tokyo: Oriental Life Insurance Cultural Development Center.

Lestari, D. A., Satyahadewi, N., \& Perdana, H. 2019. Penentuan Cadangan Premi Asuransi Jiwa Dwiguna Berjangka Dengan Metode Illinois. Bimaster: Buletin Ilmiah Matematika, Statistika Dan Terapannya, 8(3), 627-632. 
Sembiring, R. K. 1986. Buku Materi Pokok Asuransi I. Jakarta: Universitas Terbuka.

Widia, R., \& Subhan, M. 2019. Penerapan Hukum Weibull Pada Metode New Jersey Dalam Penentuan Cadangan Premi Asuransi Dwiguna Status Joint Life. UNPjoMath, 2(3), 39-43. 